\title{
EL VOTO PREFERENCIAL EN EL PERÚ
}

PREFERENTIAL VOTING IN PERU

\author{
Jorge Armando Rodríguez Vélez ${ }^{1}$ \\ Representante de las Facultades de Derecho de las universidades \\ privadas ante el Jurado Nacional de Elecciones \\ joargearv27@gmail.com
}

Perú

\section{SUMARIO}

- Introducción

- Antecedentes del voto preferencial

- ¿Cuán democrática ha resultado la experiencia de la aplicación del voto preferencial?

- Efectos del voto preferencial en los diferentes actores electorales

- Desventajas del voto preferencial

- Conclusiones

\section{RESUMEN}

El artículo desarrolla la historia del surgimiento del voto preferencial en el Perú y los objetivos que perseguía para, posteriormente, evaluar la utilidad de dicho mecanismo en el escenario actual. Las desventajas que acarrea este mecanismo para las organizaciones políticas, candidatos y el propio elector conducen, necesariamente, a evaluar alternativas de reforma en favor de la estabilidad del sistema político y la gobernabilidad.

\section{ABSTRACT}

The article develops the history of the emergence of the preferential vote in Perú and the objectives that it pursued, in order to evaluate the utility of this mechanism in the current scenario. The disadvantages that this mechanism entails for political organizations, candidates and the elector itself, necessarily lead to evaluate reform alternatives in favor of the stability of the political system and governability.

\section{PALABRAS CLAVE}

Derecho electoral, legislación electoral, voto preferencial, sistema de elección congresal, fragmentación partidaria, democracia interna

\section{KEY WORDS}

Electoral law, electoral legislation, preferential voting, system of legislative election, party fragmentation, internal democracy

Todos los canales de televisión privados vomitaban desde la mañana hasta la noche las caras de nuestros candidatos, en avisos donde el derroche se conjugaba a menudo con el mal gusto, y en los que muchos ofrecían todo lo imaginable $y$ concebible, sin importarles que ello estuviera en flagrante contradicción con los principios más elementales de aquella filosofía liberal que, decía yo, era la nuestra. Unos prometian obras públicas y otros controlar los precios y crear nuevos servicios, pero la mayoría no hacía referencia a idea alguna y se limitaba a promocionar su cara y su número, de manera chillona y machacante.

(Vargas Llosa, 2002, p. 458)

\section{INTRODUCCIÓN}

El voto preferencial surgió con el propósito de permitir a la ciudadanía elegir a un candidato de su preferencia dentro de una determinada lista congresal. En ese sentido, faculta a los ciudadanos a escoger no solo una lista de candidatos, sino también a expresar 1 Ph.D. con especialización en estudios legales, por la Atlantic International University, EE.UU. Doctor en Derecho por la Universidad
Alas Peruanas, Perú. 
preferencias ordinales respecto a los integrantes de la lista elegida, pudiendo alterar, así, el orden propuesto por los partidos políticos.

Actualmente, dicho orden de las listas de candidatos procede, o debe proceder, como resultado de los procesos de democracia interna celebrados por las organizaciones políticas; sin embargo, esto no siempre fue así, siendo que el orden de prelación de los candidatos podía ser acordado internamente y no estaba necesariamente regido por elecciones internas.

Desde el 2003 contamos con una ley que regula las organizaciones políticas en aspectos fundamentales, como la obligatoriedad de la democracia interna para la conformación de las fórmulas y las listas de candidatos. Es en ese escenario que analizamos la utilidad actual de la aplicación del mecanismo del voto preferencial, a efectos de evaluar si este habría cumplido sus objetivos inicialmente trazados, y, de ser así, si resulta o no coherente su mantenimiento en el marco legal electoral, o si, por el contrario, se ha tornado nocivo para la institucionalización y el fortalecimiento de los partidos políticos en nuestro país.

\section{ANTECEDENTES DEL VOTO PREFERENCIAL}

El voto preferencial surgió en nuestro país en 1977 a raíz de la convocatoria para conformar la Asamblea Constituyente que hiciera, mediante el Decreto Ley N. ${ }^{\circ} 21949$, el autodenominado Gobierno Revolucionario de la Fuerza Armada, presidido por el general de división EP Francisco Morales Bermúdez. Esta elección, que tuvo lugar el 4 de julio de 1978, tuvo como finalidad exclusiva la dación de una nueva Constitución Política del Estado.

Para tal efecto, el 15 de noviembre de 1977, el gobierno de facto aprobó el Decreto Ley N. ${ }^{\circ} 21995$, denominado Ley de Elecciones para la Asamblea Constituyente, en cuyo segundo considerando se señalaba que en el procedimiento para elegir a los representantes de dicho órgano se utilizaría el método «de la cifra repartidora, con la variante del voto preferencial». En ese mismo sentido, el artículo $55 .^{\circ}$ establecía que «el elector votará, al mismo tiempo, por la lista que escoja y por un candidato de su preferencia integrante de ella». Esa sería la primera vez que se mencione expresamente en una norma la referencia al voto preferencial.
Ese fue entonces el escenario en el que se introdujo tal mecanismo en nuestra historia electoral, en un contexto marcado por la crítica a los partidos políticos y un cambio de visión respecto del rol que cumplían hasta entonces, como bien señala Roncagliolo (1996):

\begin{abstract}
Antes, en efecto, se suponía que los partidos eran los representantes de la ciudadanía. A partir de los años setenta surge, cada vez con más fuerza, la imagen de los partidos como dominadores de la ciudadanía, que debe poder limitarlos y controlarlos. Este cambio de percepción llevó, en tiempos del gobierno militar peruano, a una densa discusión intelectual y política sobre las "oligarquías partidarias". Es en este contexto que emerge el voto preferencial en el Perú (p. 3).
\end{abstract}

$\mathrm{Al}$ respecto, recordemos que, entonces, la conformación de listas de candidatos no estuvo necesariamente regida por procedimientos internos democráticos. Además, la forma de elección y prelación de los integrantes de las listas de candidatos de las organizaciones políticas no estaba sometida a normas de elección democrática, sino que se regía exclusivamente por la propia normativa interna de las organizaciones.

Como bien señala Carlo Magno Salcedo (2008, p. 7), la regulación sobre las organizaciones políticas, antes de 2003 - año en que se publicó la Ley N. ${ }^{\circ}$ 28094, Ley de Organizaciones Políticas (en adelante LOP) —, comprendía solo algunos artículos relacionados a los requisitos para alcanzar la inscripción en el Registro de Partidos Políticos, circunscritos a la recolección de determinado número de firmas para respaldar la solicitud de inscripción. Por ello, la dación de la LOP, precisamente, tuvo entre sus objetivos la institucionalización de los partidos políticos a través de la exigencia de mayores requisitos para su inscripción y de la democratización de su vida interna, entre otros. En tal sentido, una primera aproximación a los orígenes del voto preferencial en nuestro país nos lleva a advertir que no fue resultado de una exigencia directa de la ciudadanía, ni fue dictado por un gobierno democrático o legítimamente elegido, sino que nace de una norma impuesta por un gobierno autoritario, en un contexto de desconfianza hacia la labor y el rol de los partidos políticos.

Posteriormente, el voto preferencial no se aplicaría en las Elecciones Generales de 1980, dado que la Constitución Política de 
1979 , en sus cuarta y quinta disposiciones generales y transitorias, dispuso que el proceso electoral 1979-80 se regiría por el Decreto Ley N. ${ }^{\circ} 14250$, debiendo observarse la elección de los senadores y diputados «por el sistema de la cifra repartidora, sin voto preferencial y siguiéndose el orden de cada lista», siendo que el senado se elegiría en distrito nacional único, mientras que las diputaciones se repartirían entre los distritos electorales correspondientes, en proporción a la densidad electoral y demográfica de cada uno.

En esa misma línea de ideas, el Decreto Ley N. ${ }^{\circ} 22652$, del 27 de agosto de 1979 -que aprobó las normas que regirían las elecciones generales de 1980 para elegir presidente, primer y segundo vicepresidentes, senadores y diputados, para el periodo 1980-1985 - se basó principalmente en el referido estatuto electoral de 1962, aprobado mediante Decreto Ley N. ${ }^{\circ}$ 14250. Tenía algunas modificaciones, entre las cuales figura el artículo $22^{\circ}$, que modifica, a su vez, el artículo $56 .^{\circ}$ del Decreto Ley N. ${ }^{\circ} 14250$, para señalar que la elección de senadores y diputados se haría por el sistema proporcional, aplicándose el método de la cifra repartidora, sin voto preferencial y siguiéndose el orden de cada lista separadamente.

El motivo de este cambio podría estar, como refiere Fernando Tuesta Soldevilla (2013), en que «la Constitución de 1979 consagró el voto para los analfabetos. En esa medida, estaban incapacitados para ejercer obligatoriamente su voto, toda vez que no saben escribir» (p. 206).

Luego, ya durante el gobierno democrático de Fernando Belaúnde Terry, se promulgó y entró en vigencia la Ley N. ${ }^{\circ} 23903$, de fecha 24 de agosto de 1984, que convocó a elecciones generales para el periodo 1985-1990. Esta modificó varios artículos del estatuto electoral de 1962, siendo una de las modificaciones más importantes la introducción del voto preferencial para la elección de diputados y senadores, pero, en esta oportunidad, opcional y con un solo voto preferencial. Así, el artículo $10 .^{\circ}$ de la Ley N. ${ }^{\circ} 23903$ señalaba lo siguiente: «Hay representación proporcional en la elección pluripersonal de senadores y diputados, mediante el método de cifra repartidora»y agrega: «La elección de senadores y diputados se hace con voto preferencial opcional».

Años después, se dicta la Ley N. ${ }^{\circ} 26859$, Ley Orgánica de Elecciones, el 29 de setiembre de
1997, que en su artículo $21 .^{\circ}$ establece que la elección de congresistas de la República se realiza bajo el método de la cifra repartidora y con doble voto preferencial opcional, lo que, dicho sea de paso, se encuentra vigente a la fecha. A decir de Roncagliolo (1996), la razón para incrementar el voto preferencial de uno a doble fue debido a que la opción única solo alcanzaba para expresar lealtad y militancia a los jefes partidarios, mientras que el doble voto preferencial era el que realmente introducía la competencia y la injerencia ciudadana en la nominación de los parlamentarios (p. 4).

Lo glosado líneas arriba ha sido el iter legislativo que ha tenido a través del tiempo el voto preferencial en nuestro país, que pasó de ser una figura surgida durante un gobierno autoritario $\mathrm{y}$ que, pese a haberse retomado en época democrática con algunas variaciones como la calidad de opcional y de doble voto preferencial, no tiene rango constitucional hasta la fecha.

\section{¿CUÁN DEMOCRÁTICA HA RESULTADO LA EXPERIENCIA DE LA APLICACIÓN DEL VOTO PREFERENCIAL?}

El mecanismo del voto preferencial aplicado en nuestro país consiste en que el elector marca el símbolo de la organización política de su preferencia, y luego puede escoger a dos candidatos de la lista de dicha organización escribiendo sus números. Así, este mecanismo genera la necesidad de realizar dos escrutinios al finalizar el acto electoral, el primero dirigido a contar el total de votos que obtuvo cada organización política, y el segundo, dirigido a contar el total de votos que obtuvo cada candidato. Por su parte, el primer escrutinio determinará cuántos candidatos resultarán elegidos de cada organización política que logre pasar la valla electoral, y el segundo escrutinio determinará quiénes serán esos candidatos elegidos. En caso de no registrarse ningún voto preferencial, sería el orden de la lista de candidatos lo que determinaría a los elegidos.

De la experiencia del último proceso de Elecciones Generales 2016, podemos apreciar que 18751264 personas votaron a nivel nacional para las elecciones congresales, de los cuales se registraron 12194042 votos válidos a favor de una u otra organización política y 8593495 votos preferenciales, según se indica en el cuadro 1. 
Cuadro 1. Votación preferencial en las Elecciones Congresales 2016

\begin{tabular}{|c|c|c|c|c|}
\hline \multicolumn{5}{|c|}{ ELECCIONES CONGRESALES 2016} \\
\hline & $\begin{array}{l}\text { TOTAL DE } \\
\text { VOTOS } \\
\text { EMITIDOS }\end{array}$ & $\begin{array}{l}\text { TOTAL DE } \\
\text { VOTOS } \\
\text { VÁLIDOS }\end{array}$ & $\begin{array}{l}\text { TOTAL DE VOTOS } \\
\text { PREFERENCIALES }\end{array}$ & $\begin{array}{c}\text { TOTAL DE } \\
\text { VOTANTES } \\
\text { PREFERENCIALES* }\end{array}$ \\
\hline AMAZONAS & 193506 & 118942 & 67936 & 33968 \\
\hline ÁNCASH & 657643 & 395580 & 227259 & 113630 \\
\hline APURÍMAC & 219035 & 140516 & 76383 & 38192 \\
\hline AREQUIPA & 895975 & 606596 & 449618 & 224809 \\
\hline AYACUCHO & 326320 & 208621 & 117154 & 58577 \\
\hline CAJAMARCA & 779859 & 530123 & 284983 & 142492 \\
\hline CALLAO & 644015 & 423430 & 237874 & 118937 \\
\hline CUSCO & 745227 & 474446 & 298223 & 149112 \\
\hline HUANCAVELICA & 201387 & 125126 & 67594 & 33797 \\
\hline HUÁNUCO & 392572 & 234383 & 128052 & 64026 \\
\hline ICA & 510493 & 339996 & 216524 & 108262 \\
\hline JUNÍN & 707486 & 446030 & 273758 & 136879 \\
\hline LA LIBERTAD & 1065713 & 736528 & 568461 & 284231 \\
\hline LAMBAYEQUE & 741036 & 502507 & 340906 & 170453 \\
\hline $\begin{array}{l}\text { LIMA + RESIDENTES } \\
\text { EN EL EXTRANJERO }\end{array}$ & 6465674 & 4309809 & 3655631 & 1827816 \\
\hline LIMA PROVINCIAS & 592915 & 384276 & 214700 & 107350 \\
\hline LORETO & 442408 & 255281 & 164627 & 82314 \\
\hline MADRE DE DIOS & 77244 & 42209 & 21688 & 21688 \\
\hline MOQUEGUA & 115862 & 77632 & 54194 & 27097 \\
\hline PASCO & 140,613 & 83,907 & 53835 & 26918 \\
\hline PIURA & $1,048,012$ & 679,332 & 387571 & 193786 \\
\hline PUNO & 733,907 & 464,488 & 303036 & 151518 \\
\hline SAN MARTÍN & 446,696 & 232,431 & 124052 & 62026 \\
\hline TACNA & 219,198 & 150,636 & 109540 & 54770 \\
\hline TUMBES & 130240 & 81597 & 60847 & 30424 \\
\hline UCAYALI & 258228 & 149620 & 89049 & 44525 \\
\hline TOTALES & \begin{tabular}{ll|}
18 & 751 \\
264 & \\
\end{tabular} & 12194042 & 8593495 & 4307592 \\
\hline
\end{tabular}

Fuente: Elaboración propia sobre la base de información publicada en el portal web institucional de la Oficina Nacional de Procesos Electorales tras las Elecciones Congresales 2016. 
Ahora bien, cabe precisar que todo elector dispone de la posibilidad de ejercer uno o dos votos preferenciales; sin embargo, tal detalle del uso del voto preferencial es solo conocido durante el escrutinio en la mesa de votación, pero no se traslada al acta electoral, razón por la cual no se puede llegar a conocer con exactitud el número de electores que opta por el voto preferencial.

Para efectos del presente análisis, se asume que todo elector optó por el doble voto preferencial, por lo cual, la cifra del total de votantes preferenciales se obtiene de dividir entre dos el total de votos preferenciales emitidos. Ello se da con excepción de la circunscripción electoral de Madre de Dios, a la cual se le asigna un solo escaño y, por ello, en la misma solo se puede emitir un voto preferencial. Así, para dicho caso, el total de votos preferenciales es igual al total de electores que hacen uso del voto preferencial.

De ese modo, por ejemplo, se aprecia que Huánuco fue una de las circunscripciones electorales donde se registró el menor uso del voto preferencial, dado que, de un total de 234383 personas que votaron por alguna de las organizaciones políticas en contienda, se emitieron 128052 votos preferenciales, que dio un total de 64026 personas que hicieron uso del voto preferencial. Es decir que 170357 personas optaron por marcar solo el símbolo de la organización política de su preferencia, aceptando con ello que prime el orden de candidatos consignado en la lista, mientras que 64026 optaron por ejercer el doble voto preferencial.

De igual forma, San Martín registró, de un total de 232431 votos válidos, 124052 votos preferenciales, dando un total de 62026 personas que hicieron uso del voto preferencial. De estas, 170405 personas optaron por marcar solo el símbolo de la organización política de su preferencia, mientras que 62026 optaron por ejercer el doble voto preferencial.

Asimismo, el Callao registró, de un total de 423430 votos válidos, 237874 votos preferenciales, dando un total de 118937 personas que hicieron uso del voto preferencial. De ellas, 304493 personas optaron por marcar solo el símbolo de la organización política de su preferencia, mientras que 118937 optaron por ejercer el doble voto preferencial.
Por otra parte, entre las circunscripciones electorales que hicieron mayor uso del voto preferencial se encuentra Lima - que incluye a los electores residentes en el extranjero-, dado que, de un total de 4309809 personas que votaron por alguna de las organizaciones políticas en contienda, se emitieron 3655631 votos preferenciales. Esto dio un total de 1827816 personas que hicieron uso del voto preferencial, con lo cual se aprecia que 2481993 personas optaron por marcar solo el símbolo de la organización política de su preferencia, aceptando con ello que prime el orden de candidatos consignado en la lista, mientras que 1827816 optaron por ejercer el doble voto preferencial.

Por su parte, Arequipa registró, de un total de 606596 votos válidos, 449618 votos preferenciales, dando un total de 224809 personas que hicieron uso del voto preferencial. De estas, 381787 optaron por marcar solo el símbolo de la organización política de su preferencia, mientras que 224809 personas optaron por ejercer el doble voto preferencial.

En el mismo sentido, Tumbes registró, de un total de 81597 votos válidos, 60847 votos preferenciales, dando un total de 30424 personas que hicieron uso del voto preferencial. De ellas, 51173 optaron por marcar solo el símbolo de la organización política de su preferencia, mientras que 30424 personas optaron por ejercer el doble voto preferencial.

Respecto a la circunscripción electoral de Madre de Dios, en la cual, como mencionamos, los electores solo emiten un voto preferencial, de 42209 personas que votaron por alguna de las organizaciones políticas en contienda, 21688 hicieron uso del voto preferencial. Es decir, que 20521 personas optaron por marcar solo el símbolo de la organización política de su preferencia, mientras que 21688 optaron por ejercer el voto preferencial.

De ello se verifica que el porcentaje de votantes preferenciales en relación con los votos válidos representa para Huánuco y San Martín solo un $27 \%$ y para el Callao, un $28 \%$, mientras que para las circunscripciones electorales de Arequipa y Tumbes representa un $37 \%$, para Lima y los electores residentes en el extranjero, un $42 \%$, y para Madre de Dios, un $51 \%$, según se indica en el cuadro 2. 
Cuadro 2. Porcentajes de uso del voto preferencial en las Elecciones Congresales 2016

\begin{tabular}{|c|c|c|}
\hline \multicolumn{3}{|c|}{ ELECCIONES CONGRESALES 2016} \\
\hline & $\begin{array}{c}\text { TOTAL DE VOTANTES } \\
\text { PREFERENCIALES EN RELACIÓN } \\
\text { CON LOS VOTOS VÁLIDOS }\end{array}$ & $\begin{array}{l}\text { TOTAL DE VOTANTES } \\
\text { PREFERENCIALES EN } \\
\text { RELACIÓN CON LOS } \\
\text { VOTOS EMITIDOS }\end{array}$ \\
\hline AMAZONAS & $29 \%$ & $18 \%$ \\
\hline ÁNCASH & $29 \%$ & $17 \%$ \\
\hline APURÍMAC & $27 \%$ & $17 \%$ \\
\hline AREQUIPA & $37 \%$ & $25 \%$ \\
\hline AYACUCHO & $28 \%$ & $18 \%$ \\
\hline CAJAMARCA & $27 \%$ & $18 \%$ \\
\hline CALLAO & $28 \%$ & $18 \%$ \\
\hline CUSCO & $31 \%$ & $20 \%$ \\
\hline HUANCAVELICA & $27 \%$ & $17 \%$ \\
\hline HUÁNUCO & $27 \%$ & $16 \%$ \\
\hline ICA & $32 \%$ & $21 \%$ \\
\hline JUNÍN & $31 \%$ & $19 \%$ \\
\hline LA LIBERTAD & $39 \%$ & $27 \%$ \\
\hline LAMBAYEQUE & $34 \%$ & $23 \%$ \\
\hline $\begin{array}{l}\text { LIMA + RESIDENTES EN EL } \\
\text { EXTRANJERO }\end{array}$ & $42 \%$ & $28 \%$ \\
\hline LIMA PROVINCIAS & $28 \%$ & $18 \%$ \\
\hline LORETO & $32 \%$ & $19 \%$ \\
\hline MADRE DE DIOS & $51 \%$ & $28 \%$ \\
\hline MOQUEGUA & $35 \%$ & $23 \%$ \\
\hline PASCO & $32 \%$ & $19 \%$ \\
\hline PIURA & $29 \%$ & $18 \%$ \\
\hline PUNO & $33 \%$ & $21 \%$ \\
\hline SAN MARTÍN & $27 \%$ & $14 \%$ \\
\hline TACNA & $36 \%$ & $25 \%$ \\
\hline TUMBES & $37 \%$ & $23 \%$ \\
\hline UCAYALI & $30 \%$ & $17 \%$ \\
\hline TOTALES & $35 \%$ & $23 \%$ \\
\hline
\end{tabular}

Fuente: Elaboración propia sobre la base de información publicada en el portal web institucional de la Oficina Nacional de Procesos Electorales tras las Elecciones Congresales 2016. 
Asimismo, se aprecia que, en relación con el total de votos válidos, solo el $35 \%$ corresponde a votos preferenciales a nivel nacional y de peruanos en el extranjero, lo cual significa que los votantes preferenciales representan, a su vez, el $23 \%$ del total de votos emitidos. Esta situación revela que, salvo en la circunscripción de Madre de Dios, la mayoría de electores no ejerce el voto preferencial y se limita a marcar el símbolo de la organización política de su preferencia. No obstante, y pese a ser mayoría, no son ellos quienes deciden qué candidatos salen elegidos, sino que tal decisión recae en los electores que ejercieron el voto preferencial, sin importar que sean una minoría.

En nuestro actual sistema de elección congresal, mediante listas cerradas pero no bloqueadas y con doble voto preferencial opcional, se verifica que el elector que no ejerce su voto preferencial solo genera incidencia en la cantidad de candidatos que alcanzarán un escaño, pese a que, al no marcar un candidato preferido, tácitamente estaría dando su consentimiento al orden de la lista propuesto por su organización política elegida. No obstante, no existen mecanismos para permitirle a ese elector hacer valer su decisión o manifestar su respaldo en favor del orden de la lista, y con ello rechazar el voto preferencial. Efectivamente, así ocurre, siendo tal vez el ejemplo más claro el de la circunscripción electoral de Moquegua, donde, de 115862 electores que sufragaron en las elecciones congresales, 27097 electores preferenciales fueron quienes determinaron que resultaran elegidos los candidatos 2 y 3 de las dos organizaciones políticas que obtuvieron mayor cantidad de votos. ${ }^{2}$ De ahí que el disminuido uso del voto preferencial permite cuestionar cuán democrático es realmente este mecanismo de elección que, si bien a primera vista aparenta brindarle al ciudadano un mayor poder de decisión respecto a la elección de sus representantes al Congreso, en la práctica se verifica que su uso opcional y menor genera el efecto inverso, dado que los electores que optan por ejercer el voto preferencial terminan imponiéndose frente a quienes no hacen uso de él, incluso cuando estos últimos son mayoría.

En tal medida, se justifica la necesidad de una reforma que permita arribar a un mejor sistema

2 Mario Fidel Mantilla Medina, candidato 2 de la organización política Fuerza Popular y Vicente Antonio Zeballos Salinas, candidato 3 de la organización política Peruanos por el Kambio. electoral con contrapesos que conlleven una mejor representación, ya sea a través de la eliminación del voto preferencial o de sistemas mixtos en los que se considere, por ejemplo, el porcentaje de participación de la población y del uso del voto preferencial. Así, solo si más de la mitad de electores hace uso del voto preferencial, este podría operar; de otro modo, debería primar el orden de la lista.

\section{EFECTOS DEL VOTO PREFERENCIAL EN LOS DIFERENTES ACTORES ELECTORALES}

Colocándonos en la posición de los diversos actores en un proceso electoral desde el punto de vista del elector - por ejemplo, del distrito electoral de Lima metropolitana, donde se eligen a 36 representantes al Congreso-, el elector tiene la posibilidad de marcar dos candidatos preferenciales. Para ello, un voto informado requeriría por lo menos conocer los antecedentes, trayectoria, propuestas y hojas de vida de los 36 candidatos presentados por el partido de su elección, ello sin considerar a los candidatos presentados por las otras listas en contienda.

Por el contrario, la realidad indica que solo los candidatos que alcancen mayor notoriedad serán los elegidos, ya sea a través de propaganda política o por su presencia en los medios, por tratarse de personas públicas, deportistas famosos, periodistas, críticos, etcétera. Ergo, la práctica de un voto informado en los sistemas de voto preferencial puede convertirse en una utopía.

Si bien a primera vista el voto preferencial da la apariencia de ampliar el poder de decisión de los electores, al permitirles reordenar las listas de candidatos al Congreso también los enfrenta a una gran diversidad de opciones, todas disímiles, que dificultan al ciudadano promedio la toma de una decisión informada y consciente, reforzando el peligro de recaer en el voto emocional e irresponsable.

Ahora, desde el punto de vista del candidato, encontramos que este se ve compelido a embarcarse en una doble campaña, en favor de su organización política y en su beneficio particular, especialmente en este segundo caso, cuando no haya logrado ocupar un lugar privilegiado en la lista de candidatos. 
Esta situación le demanda al candidato, a su vez, generar su propia campaña, la cual le demanda recaudar fondos y embarcarse en una contienda con quienes son, al final de cuentas, sus compañeros de lista. Igualmente, una vez que el candidato es electo como representante gracias a sus votantes preferentes, este siente que se debe a ellos y no a su partido político, lo que deviene e divisionismos en partidos y bancadas, y dificulta la formación de consensos en la labor parlamentaria.

Con relación a las organizaciones políticas, vemos cómo el voto preferencial tiene graves efectos sobre la disciplina partidaria, el transfuguismo y la propia labor parlamentaria en las diferentes bancadas. Dado que los candidatos favorecidos con el voto preferencial sienten que obtuvieron su elección por mérito propio y en contra de lo decidido por su organización partidaria, las organizaciones políticas pierden cohesión y dirección sobre los actos de sus candidatos una vez que son electos, situación que se incrementa a lo largo del ejercicio del periodo de Gobierno, donde el candidato puede orientar su labor y discurso más hacia la propia reelección que hacia la doctrina y planes promovidos por la organización política.

Al respecto, cabe mencionar lo señalado por Hurtado (2004) cuando, al referirse a la relación directa que genera el voto preferencial entre el candidato y su electorado, señala que «este poder de atracción mediatiza el papel del partido como canalizador y facilitador de las demandas populares y debilita la participación institucional del elector como adherente o militante del mismo» (p. 6).

En suma, si bien por un lado el voto preferencial aparenta ampliar el poder de decisión de los electores, esto naturalmente incide en el incremento de la oferta electoral, dado que ya no se vota por una lista, sino que se puede votar, además, por cada candidato de la misma, afectándose con ello la posibilidad de ejercer un voto verdaderamente informado en beneficio del «voto emocional». Asimismo, los candidatos electos adquieren gran protagonismo gracias al voto preferencial, y esto, lejos de serles positivo, los puede llevar a prácticas clientelistas con sus votantes en desmedro de las líneas programáticas de su organización política o de las decisiones que se adopten como bancada. Esto, a su vez, mella la labor parlamentaria y convierte a los partidos en simples vehículos o franquicias para la participación en procesos electorales, en desmedro del rol que la Constitución y la Ley de Organizaciones Políticas les otorgan como legítimos representantes de la voluntad ciudadana y canales para la participación ciudadana en política.

\section{DESVENTAJAS DEL VOTO PREFERENCIAL}

\section{Debilitamiento de la institucionalidad de los partidos politicos}

\section{- Afectación a la disciplina partidaria: Fragmentación parlamentaria y transfuguismo}

Son diversos los efectos que el voto preferencial tiene en la institucionalidad partidaria, siendo estos, principalmente, negativos. En un régimen como el nuestro, en el que se postula a cargos de elección popular a través de listas y fórmulas conformadas por las organizaciones políticas, el rol de estas se está limitando a ser meros vehículos para acceder al poder.

El protagonismo que con el voto preferencial adquieren los candidatos al Parlamento sustituye a la contienda de ideas y programas partidarios. Esta situación genera, a su vez, que estos candidatos, una vez elegidos, se conviertan en representantes muchas veces desarraigados, independientes, no sujetos a la disciplina partidaria, candidatos sobre cuya línea ideológica o principios poco se podría prever. Evidentemente, esto dificulta la adopción de consensos en el Parlamento.

Por otra parte, en función a la personalización que produce en la relación entre elector y representante, el voto preferencial ha sido analizado como uno de los elementos que conlleva el transfuguismo político. Sobre el particular, Delgado (2009) exploraba como supuesto general el hecho de que, mientras la elección se realice en términos más personales que partidarios $-\mathrm{o}$ en bloque-, mayor sería la posibilidad de que el candidato, una vez elegido, se ubique en otro grupo parlamentario que beneficie más su carrera de congresista o «en el que le quepa explotar mejor la calidad 
del vínculo personal más favorable en relación con el elector» (p. 229).

En dicho estudio, centrado en las prácticas de transfuguismo de los años 2001 a 2006, se concluye que «sí cabe advertir y constatar que existe alguna relación entre la regla que reconoce el doble voto preferencial y la posibilidad de que beneficiarse del mismo incentive la defección partidaria» (p. 236). Así pues, señala que el transfuguismo se da con mayor frecuencia entre los representantes que mejoran su puesto que entre quienes empeoran respecto del puesto de su postulación inicial. Declara que:

\begin{abstract}
Este dato permite suponer y, en su caso, ceteris paribus, predecir que habrá mayor transfuguismo en los casos en los que las listas de los partidos se vean afectadas por el voto preferencial. Esta presunción confirmaría la inclinación de quienes postulan a la eliminación de formas más personalizadas del voto con la finalidad de fortalecer el papel intermediador de los partidos políticos. Se trataría de un caso en el que, en efecto, puede advertirse que la personalización del voto disminuye la capacidad de los partidos para cumplir con las expectativas institucionales que le asigna el sistema -vale decir, su capacidad para minimizar la adopción de acuerdos de base local y particular, y para maximizar las posibilidades de tomar acuerdos y adoptar políticas parlamentarias de carácter general o nacional- (p. 233).
\end{abstract}

Así, el voto preferencial no resulta ser una herramienta que actualmente aporte algo positivo al sistema de representación, en tanto mella los esfuerzos por el fortalecimiento del sistema de partidos. Además, es un factor que conlleva la fragmentación parlamentaria y que convierte en intrascendente el rol de los partidos políticos.

\section{- Pugna entre candidatos de un mismo partido}

El voto preferencial ha sido una razón de enfrentamientos y hasta luchas fratricidas entre los propios compañeros de partido, debido a que el candidato tiene que librar dos batallas: luchar porque su organización política gane la mayor cantidad de escaños, y luchar por obtener más votos que sus propios compañeros para poder ocupar uno de los escaños alcanzados por la organización política. En consecuencia, los candidatos compiten entre compañeros de lista y convierten al correligionario en un oponente más.

\section{- Campañas electorales personalistas}

Esta pugna entre candidatos tiene efectos adversos, a su vez, en la forma que adquieren las campañas electorales para acceder al Parlamento.

Si bien señalábamos que un elector consciente debe elegir en función de ideas y propuestas, más que en función de las personas, el voto preferencial en realidad invita a todo lo contrario, porque las campañas personalistas dan lugar a representantes que se consideran independientes, que sienten que, por su propio mérito, lograron un escaño y un lugar de importancia que les fue negado en la elección interna partidaria. En palabras de Brenes y Matarrita (2012):

Los representantes elegidos vía voto preferente, dado su esfuerzo personal para conseguir la victoria en las elecciones, eventualmente podrían llegar a sentirse dueños del asiento que ocupan. Su lucha en solitario - pensarán ellos-es salvoconducto suficiente para un ejercicio independiente del poder $y$, ante esto, la democracia se encuentra en jaque (p. 52).

Por ello mismo, resulta difícil cambiar o eliminar el sistema de elección parlamentaria por voto preferencial, cuando quienes detentan el Poder lo han alcanzado, precisamente, mediante este mecanismo.-

\section{- Sobreexposición a campañas publicitarias}

Es un tema recurrente de estudio el efecto que tiene en la ciudadanía la sobrexposición a spots televisivos, en detrimento del ejercicio de un voto plenamente informado. Aunado al hecho de que el voto preferencial genera una competencia ya no solo entre partidos políticos sino también entre los candidatos de cada partido, ello coloca al elector ante tantas campañas publicitarias como candidatos haya, viéndose expuesto a innumerables mensajes publicitarios en los diferentes medios de comunicación. Esto dificulta la toma de una decisión consciente con base en información relevante. 


\section{- Propuestas de campaña ajenas al plan institucional del partido político}

En el mismo sentido, la excesiva competencia en dos frentes (en favor del partido y en favor de la propia candidatura) genera en el candidato un incentivo para la demagogia. A su vez, olvidando que los congresistas no tienen iniciativa de gasto o iniciativa legislativa de demarcación territorial, por ejemplo, se escuchan promesas de campaña que exceden las prerrogativas del cargo al que aspiran, llevando con ello al elector a la desinformación y la confusión.

La experiencia demuestra que el voto preferencial ha contribuido a incentivar las candidaturas personalistas y clientelismos por parte de candidatos que, cuando salen electos, privilegian un discurso personal orientado a la reelección. Este podría no guardar coherencia con la línea ideológica o plan de trabajo de su partido.

\section{Peligro de financiamiento ilícito en las campañas individuales}

Vemos cómo con el voto preferencial se traslada la contienda electoral al interior de los partidos políticos, por lo que los candidatos, al pugnar por alcanzar un escaño, se embarcan en campañas individuales que necesariamente requieren de financiamiento para su difusión.

En ese escenario, los candidatos se ven compelidos a conseguir fondos para financiar sus campañas personales, siendo proclives a recibir financiamiento de fuentes ilícitas y financiamiento directo no reportado a sus respectivas organizaciones ni a los organismos electorales. Estos aportes directos a las campañas pueden escapar a la supervisión o control del propio partido político y deviene en una mayor dificultad para los organismos electorales ejercer un control efectivo sobre el financiamiento político cuando existe la posibilidad de realizar campañas individuales como las que comentamos.

\section{No conlleva una mejor representatividad}

Se ha señalado que el voto preferente pretende optimizar la relación entre el elector y su representante en el Poder; sin embargo, como bien señalan Brenes y Matarrita (2012), «la demanda para 'acercar' el diputado al ciudadano pareciera encontrarse en otros instrumentos, no necesariamente en el voto preferente». Uno de esos instrumentos sería asegurar la responsabilidad política de los representantes mediante sistemas de rendición de cuentas, donde el desempeño del parlamentario es sometido a constante evaluación ciudadana, con posibilidad de revocatoria del mandato.

Asimismo, con relación a esos otros mecanismos que pueden implementarse para garantizar prácticas más democráticas en los sistemas electorales y que conlleven a una mejor representatividad, recordemos la observación efectuada por Hurtado Cruz con respecto al porcentaje de libre designación de candidatos del cual gozan las organizaciones políticas, conforme a lo dispuesto en el artículo $24 .^{\circ}$ de la Ley N. $^{\circ}$ 28094, Ley de Organizaciones Políticas, el cual fue incluso incrementado de $20 \%$ a $25 \%$ a partir de la Ley N. ${ }^{\circ} 30414$, publicada el 17 de enero de 2016. La libre designación de candidatos permite a los partidos políticos excluir a determinados postulantes de los procesos de democracia interna y colocarlos directamente en las listas de candidatos que luego serán sometidas a elección popular. Así pues, si la eliminación del voto preferencial no va acompañada de la eliminación de esta prerrogativa, nos veríamos enfrentados al peligro de convertirnos en una «democracia elitista», por lo que una reforma debería contemplar «que las candidaturas de cada partido se designen solo en elecciones internas con voto universal, libre, voluntario, igual, directo y secreto de los afiliados y no afiliados, trasladando el voto preferencial a esta instancia y otorgando a los resultados carácter vinculante en el orden de conformación de las listas» (Hurtado, 2004, p. 6).

Otra alternativa en debate es la de la elección individual en distritos electorales unipersonales, donde la elección se limitaría a un solo congresista por circunscripción. La competencia se concentraría entre candidatos de diferentes organizaciones políticas y ya no entre integrantes de una misma lista, disminuyendo con ello el número de opciones a elegir y haciendo viable la emisión de un voto informado. 


\section{Complejidad en la elección parlamentaria}

La multiplicidad de opciones de elección que produce el voto preferencial genera, naturalmente, una alta tasa de incidencia de errores en el conteo de votos en mesa, lo que deviene en la consiguiente observación de actas y en resoluciones de anulación de votos $\mathrm{y}$ de actas. Pese a que estas decisiones pueden ser impugnadas ante la segunda instancia electoral, resulta inevitable la demora en la entrega de resultados electorales finales, pese a que organismos electorales como el Jurado Nacional de Elecciones laboran en sesión permanente en época electoral.

\section{CONCLUSIONES}

El voto preferencial es un mecanismo a través del cual el elector puede alterar el orden de la lista de candidatos propuesta por la organización política de su preferencia, estableciendo dentro de la misma su propio orden de preferencias.

A primera vista, se presenta como un mecanismo más democrático $\mathrm{y}$ percibido por el ciudadano como más representativo y participativo, ya que amplía su poder de decisión y le permite elegir por encima de la elección inicial realizada por la organización política. No obstante, frente a tales supuestas ventajas, se encuentran numerosas desventajas que perjudican la institucionalidad de los partidos políticos y la gobernabilidad.

Veíamos al inicio de este artículo cómo el voto preferencial surgió en nuestro país en un contexto de desconfianza hacia la labor y el rol de los partidos políticos. Ante la ausencia de normas para la conformación de las listas de candidatos, apareció el voto preferencial en el entendido de que permitía, de alguna forma, democratizar la elección de los candidatos de las organizaciones políticas. Como ya señalaba Tuesta Soldevilla (2013), «el voto preferencial, en sí mismo, no es nocivo. Pudo haber jugado un papel en la década del ochenta, pero entonces teníamos un contexto de partidos mucho más organizados. Partidos en los que además la calidad de la representación era mejor» (p. 2).

$\mathrm{Si}$ bien el voto preferencial podría haber surgido con una válida justificación, sobre la cual ya habría cumplido su objetivo, en la actualidad resulta claramente perjudicial para la construcción de un verdadero sistema de partidos que abone en favor de la gobernabilidad.

Por ello, la reforma electoral emprendida en nuestro país, para ser integral, no debería dejar pasar la oportunidad de abordar este punto. Ya Nohlen (2004) señalaba que unos de los requisitos estratégicos de un debate de reforma electoral es determinar con exactitud los objetivos de dicha reforma, saber y tener claro qué se quiere mejorar (pp. 68-69). Si coincidimos en que el fortalecimiento del sistema de partidos y su institucionalidad es uno de ellos, entonces omitir esta necesaria discusión traiciona uno de los principales objetivos de la reforma a cambio de intereses personales de quienes pretenden continuar beneficiándose del mal funcionamiento del sistema político.

El surgimiento de la LOP tuvo una clara orientación hacia el fortalecimiento e institucionalización de los partidos políticos a través de la democratización de sus elecciones internas, el control de su financiamiento y del acceso equitativo a la propaganda política en los medios de comunicación masiva. Si bien tales objetivos no se habrían alcanzado a cabalidad en el transcurso de su aplicación hasta nuestros días, siguen constituyendo parte fundamental del derrotero a seguir para el fortalecimiento de nuestro sistema electoral, del cual son parte fundamental las organizaciones políticas.

No obstante lo expuesto, la eliminación del voto preferencial tampoco solucionará por sí sola el problema de la representación congresal en nuestro país. De ahí que lo que debe promoverse es una reforma electoral integral que abarque diversos frentes, tales como democracia interna y financiamiento político, pues la eliminación del voto preferencial solo cobra sentido si se cuenta con mecanismos idóneos que articulen principalmente esos tres frentes.

Eliminar el voto preferencial, pero manteniendo el porcentaje de libre designación de candidatos, no resulta lo más adecuado. Dicha combinación nos llevaría de regreso al imperio de la voluntad de los dirigentes de los partidos políticos, quienes volverían a ser libres de designar a los candidatos sin mecanismos 
democráticos y colocándolos en los primeros lugares de las listas, desvirtuando por completo el objetivo buscado. En ese entendido, considero que es necesaria y obligatoria la intervención de los organismos electorales en los procesos de democracia interna de las organizaciones políticas, a fin de garantizar que el orden de las listas responda efectivamente a la decisión de sus integrantes, a través del voto universal y directo de los afiliados en las elecciones internas, y que así las listas sean resultado de procesos democráticos y no solo de la decisión de una cúpula partidaria.

Finalmente, es importante tener presente la observación de Nohlen (2004), cuando señala que, si bien los sistemas electorales permiten contrarrestar las falencias en la representación política, por otra parte, «vale recordar aquí nuestra advertencia de no alentar expectativas de tipo maximalista, como si fuera posible superar todos los déficits de la representación política criticados mediante los medios de la sistemática electoral, independientemente de las circunstancias reinantes» (p. 23).

Si bien los objetivos para el perfeccionamiento del sistema electoral pueden ser varios, el resultado que finalmente se busca es uno solo: la estabilidad del sistema político democrático que nos encamine en la construcción de un mejor Gobierno y, en tal forma, la eliminación del voto preferencial resulta ser una medida que corresponde priorizar, dado que contribuye directamente a tal fin.

\section{FUENTES DE INFORMACIÓN}

\section{Fuentes bibliográficas}

Brenes Villalobos, L. y Matarrita Arroyo, M. (Segundo semestre de 2012). «Efectos colaterales del voto preferente». Revista Derecho Electoral. Tribunal Supremo de Elecciones 14, pp. 41-58. Costa Rica.

Delgado Guembes, C. (2009). Fragilidad partidaria y racionalidad del transfuguismo en Latinoamérica. En Transfuguismo político: escenarios y respuestas, pp. 171-244. CivitasThomson Reuters.

Hurtado Cruz, V. (Setiembre de 2004). El voto preferencial y la democracia de partidos. Boletín informativo, 24. Jurado Nacional de Elecciones.
Nohlen, D. (2004). Sistemas electorales y reforma electoral. Una introducción (primera edición). Lima, Perú: Asociación Civil Transparencia e Internacional IDEA.

Roncagliolo, R. (Octubre de 1996). El voto preferencial en el Perú. Coronado, Panamá. Seminario Internacional sobre Reformas Electorales.

Salcedo Cuadros, C. M. (Octubre de 2008). Las vicisitudes del voto preferencial y la democracia interna en los partidos políticos en el Perú. Panorama Hemisférico, elecciones y procesos políticos en las Américas: revista informativa mensual. 00017-2008, pp. 6-7.

Tuesta Soldevilla, F. (Primer semestre de 2013). Un voto letal: el voto preferencial y los partidos políticos en el Perú. Revista de Derecho Electoral. Tribunal Supremo de Elecciones, 15, 2, pp. 251-270. Costa Rica.

La República. (10 de junio de 2013). Entrevista a Fernando Tuesta Soldevilla en el diario La República. Lima.

Vargas Llosa, Mario. (2002). El pez en el agua (2. ${ }^{a}$ edición). Lima: Ediciones Peisa.

\section{Fuentes electrónicas}

Decreto Ley $\mathrm{N}^{\circ}$ 21949, Se convoca a elecciones para la asamblea constituyente. (4 de julio del 1978). Recuperado del sitio de internet del Congreso de la Republica: http:// www.leyes.congreso.gob.pe/Documentos/ Leyes/21949.pdf

Decreto Ley $\mathrm{N}^{\circ}$ 21995, Ley de elecciones para la asamblea constituyente. (20 de noviembre de 1977). Recuperado del sitio de internet del Congreso de la Republica: http:// www.leyes.congreso.gob.pe/Documentos/ Leyes/21995.pdf

Decreto Ley $N^{\circ} 14250$, Estatuto Electoral. (s.f.). Recuperado del sitio de internet del Congreso de la Republica: http://www.leyes.congreso. gob.pe/Documentos/Leyes/14250.pdf

Decreto Ley $\mathrm{N}^{\circ}$ 22652, Aprueban normas y regirán para las elecciones generales del próximo año. (28 de agosto de 1979). Recuperado del sitio de internet del Congreso de la Republica: http://www.leyes.congreso. gob.pe/Documentos/Leyes/22652.pdf 
Ley $\mathrm{N}^{\circ} 28094$, Ley de partidos políticos. (01 de noviembre del 2003). Recuperado del sitio de internet del Congreso de la Republica: http:// www.leyes.congreso.gob.pe/Documentos/ Leyes/28094.pdf

Ley $\mathrm{N}^{\circ}$ 23903, El presidente de la republica convoca a elecciones generales con anticipación no menor de ocho meses a la fecha en que deben efectuarse. (25 de agosto de 1984). Recuperado del sitio de internet del Congreso de la Republica: http://www.leyes.congreso.gob.pe/ Documentos/Leyes/23903.pdf
Ley $\mathrm{N}^{\circ}$ 26859, Ley Orgánica de Elecciones. (01 octubre de 1997). Recuperado del sitio de internet del Congreso de la Republica: http:// www.leyes.congreso.gob.pe/Documentos/ Leyes/26859.pdf

Ley N. ${ }^{\circ} 30414$, Ley que modifica la ley 28094 , ley de partidos políticos. (17 de enero del 2016). Recuperado del sitio de internet del Congreso de la Republica: http://www2.congreso.gob. pe/Sicr/TraDocEstProc/Expvirt_2011.nsf/Rep expvirt?OpenForm $\& D b=201100009 \&$ View 